Journal of Healthcare Technology and Medicine Vol. 6 No. 1 April 2020

Universitas Ubudiyah Indonesia

e-ISSN : 261109X

\title{
Hubungan Pengetahuan Ibu Hamil Trimester Ii Dan Iii Dengan Penatalaksanaan Breast Care Di Kemukiman Busu Kecamatan Mutiara Barat Kabupaten Pidie Tahun 2018
}

\section{Relationship Of Knowledge Of Trimester Pregnant Women Ii And Iii With The Management Of Breast Care In Kemukiman Busu Kecamatan Mutiara West Pidie District In 2018}

\author{
Halimah Tussakdiah*1, Gebi Andriani², Sukmawati ${ }^{3}$ \\ Email: tusakdiahhalimah@gmail.com ${ }^{1}$ \\ Dosen Akbid Darul Husada ${ }^{1,2,3}$
}

\begin{abstract}
ABSTRAK
Tujuan Penelitian Untuk mengetahui Hubungan Pengetahuan Ibu hamil trimestrer II dan III Di Kemukiman Busu Kecamatan Mutiara Barat Kabupaten Pidie Tahun 2018. Desain Penelitian ini bersifat Analitik dengan pendekatan Cross sectional. Penelitian dilakukan mulai tanggal 27 Oktober sampai 08 November 2017. Populasi dalam penelitian adalah seluruh ibu hamil trimester II dan III berjumlah 35 orang. Sampel dalam penelitian menggunakan teknik total populasi berjumlah 35 orang. Berdasarkan Hasil penelitian menunjukan, Pengetahuan ibu hamil mayoritas berpengetahuan kurang sebanyak 16 responden (45,7\%). Penatalaksanaan Breast Care mayoritas melaksanakan perawatan payudara sebanyak 18 responden $(51,4 \%)$. Hasil analisa statistic menggunakan uji Chi-Square dengan nilai $\mathrm{P}$ value $=0,002<$ 0,05 hal tersebut berarti Ho ditolak dan Ha diterima, maka Ada Hubungan antara Pengetahuan Ibu Hamil Trimester II dan III Dengan Penatalaksanaan Breast Care.
\end{abstract}

Kata kunci : Pengetahuan ibu hamil trimester II dan III, Penatalaksanaan breast care

\section{ABSTRACT}

Research Objectives To determine the Knowledge Relationship between trimestrer II and III pregnant women in the Busu Village, Mutiara Barat District, Pidie Regency in 2018. The design of this study is analytical with a cross sectional approach. The study was conducted from 27 October to 8 November 2017. The population in the study were all pregnant women in the second and third trimesters of 35 people. The sample in this study used a total population technique of 35 people. Based on the results of the study showed that the majority of pregnant women had less knowledge as many as 16 respondents (45.7\%). Management of Breast Care, majority carried out breast care as many as 18 respondents (51.4\%). The results of statistical analysis using the Chi-Square test with $P$ value $=0.002<0.05$, this 
Journal of Healthcare Technology and Medicine Vol. 6 No. 1 April 2020

Universitas Ubudiyah Indonesia

e-ISSN : 261109X

means that Ho is rejected and Ha is accepted, so there is a relationship between Knowledge of Second and Third Trimester Pregnant Women with Breast Care Management.

Keywords: Knowledge of pregnant women in trimester II and III, management of breast care

\section{PENDAHULUAN}

Berdasarkan laporan dari Survei Demografi dan Kesehatan Indonesia (SDKI, 2007) diusia lebih dari 25 tahun sepertiga wanita di Dunia (38\%) didapati tidak menyusui bayinya karena terjadi pembengkakan payudara, dan di Indonesia angka cakupan ASI eksklusif mencapai 32,3\%. Di Provinsi Aceh dalam indikator kinerja upaya perbaikan gizi masyarakat tahun 2010 -2014 disebutkan bahwa target cakupan pemberian ASI secara eksklusif tahun 2011 adalah sebesar 67\%. Survei Demografi dan Kesehatan Indonesia (SDKI) tahun 2012-2013 menunjukkan bahwa 55\% ibu menyusui mengalami mastitis dan putting susu lecet, kemungkinan hal tersebut disebabkan karena kurangnya perawatan selama masa nifas (Anwar, 2005 dalam Nur, 2012).

Perawatan payudara merupakan salah satu bagian penting yang harus diperhatikan sebagai persiapan untuk menyusui nantinya, hal ini dikarenakan payudara merupakan organ esensial penghasil ASI pada bayi, masalah utama dan prinsip yaitu bahwa ibu-ibu membutuhkan bantuan dan informasi serta dukungan agar merawat payudara pada saat hamil untuk mempersiapkan ASI saat melahirkan sehingga menambah keyakinan bahwa mereka dapat menyusukan bayinya dengan baikserta mengetahui fungsi manfaat perawatan payudara pada saat hamil (Ronald, 2011).

Perawatan payudara sebaiknya dilakukan selama masa kehamilan yaitu pada usia kehamilan 18 minggu sampai usia kehamilan 40 minggu (Trimester II dan III) dan bukan sesudah persalinan (Geniofan, 2010).Angka Kematian Bayi (AKB) di tujuh tahun terakhir mengalami fluktuasi. Dari data yang bersumber pada dinas kesehatan kabupaten/ kota, diketahui jumlah kematian bayi di Aceh tahun 2016 sebanyak 1.108 jiwa dan lahir hidup sebanyak 100.278 jiwa. Dengan menggunakan 
Journal of Healthcare Technology and Medicine Vol. 6 No. 1 April 2020

Universitas Ubudiyah Indonesia

e-ISSN : 261109X

definisi operasional yang telah ditetapkan untuk kedua indikator tersebut maka AKB di Aceh tahun 2016 sebesar 11 per 1.000 kelahiran hidup. Angka ini menurun dari tahun sebelumnya (12/1.000 LH). Hal ini menunjukkan semakin baiknya pelayanan kesehatan di fasilitas kesehatan (Profil Kesehatan Aceh, 2016).

Berdasarkan laporan dari Survei Demografi dan Kesehatan Indonesia (SDKI, 2009) diusia lebih dari 25 tahun sepertiga wanita di Dunia (38\%) didapati tidak menyusui bayinya karena terjadi pembengkakan payudara, dan di Indonesia angka cakupan ASI eksklusif mencapai 32,3\%. Di Provinsi Aceh dalam indikator kinerja upaya perbaikan gizi masyarakat tahun 2010-2014 disebutkan bahwa target cakupan pemberian ASI secara eksklusif tahun 2011 adalah sebesar $67 \%$.

Berdasarkan laporan yang diterima dari Dinas Kesehatan Provinsi Aceh 2013 diketahui bahwa cakupan pemberian ASI secara eksklusif tahun 2013 adalah sebesar $68,3 \%$ dari target sebesar $75 \%$. Dengan menyelenggarakan program cakupan pemberian ASI secara eksklusif diharapkan target ini berhasil. Dan dari hasil wawancara dengan jumlah responden $10 \mathrm{ibu}$ postpartum, didapatkan 50\% ibu memiliki pengetahuan kurang dan $50 \%$ ibu memiliki pengetahuan baik.

Berdasarkan studi pendahuluan di Kemukiman Busu terdapat 35 ibu hamil trimester II dan III. Hasil wawancara kepada 10 ibu hamil trimester II dan III ada 6 ibu hamil mengetahui tentang perawatan payudara selama kehamilan, yaitu dengan cara memberikan mengkompres payudara dengan handuk yang telah dibasahi air hangat, dan memijat payudara, namun frekuensi dalam waktu dalam pemijatan tidak selalu sama, artinya ibu tidak melakukan pemijatan payudara setiap hari. Terdapat 4 ibu hamil, tidak mengetahui perawatan payudara selama kehamilan, oleh sebab itu keempat ibu tersebut hanya membersihan paydara pada saat mandi dan tidak melakukan pemijatan seperti menarik putting dan dipijat.

Berdasarkan latar belakang diatas, maka peneliti tertarik untuk malakukan penelitian dengan judul "Hubungan Pengetahuan Ibu Hamil Trimester II dan III Dengan Penatalaksanaan Breast Care Di Kemukiman Busu Kecamatan Mutiara Barat Kabupaten Pidie Tahun 2018”. 
Journal of Healthcare Technology and Medicine Vol. 6 No. 1 April 2020

Universitas Ubudiyah Indonesia

e-ISSN : 261109X

\section{METODE PENELITIAN}

Penelitian ini merupakan penelitian analitik, dengan menggunakan pendekatan cross sectional. Penelitian dilakukan di Desa Mee Tanjong Usi Kecamatan Mutiara Timur Kabupaten Pidie pada tanggal 28 Oktober 2019 dengan sampel seluruh ibu hamil trimester II dan III yang ada Di Kemukiman Busu Kecamatan Mutiara Barat Kabupaten Pidie berjumlah 35 orang.

\section{HASIL}

1. Karakteristik Responden Berdasarkan Umur

TABEL 5.1

KARASTERISTIK RESPONDEN IBU HAMIL TRIMESTER II DAN III DI KEMUKIMAN BUSU KECAMATAN MUTIARA BARAT KABUPATEN PIDIE BERDASARKAN UMUR

\begin{tabular}{cccc}
\hline No & Umur & Frekuensi (f) & Persentase (\%) \\
\hline $\mathbf{1}$ & $<20$ tahun & 3 & 8,6 \\
$\mathbf{2}$ & $20-35$ tahun & 27 & 77,1 \\
$\mathbf{3}$ & $>35$ tahun & 5 & 14,3 \\
& Jumlah & 35 & 100 \\
\hline
\end{tabular}

Sumber data : Data Primer (diolah tahun 2018)

Berdasarkan Tabel 5.1 menunjukkan bahwa dari 35 responden, mayoritas reseponden berumur antara 20-35 tahun yaitu 27 reponden $(77,1 \%)$.

2. Karakteristik Responden Berdasarkan Umur 
Journal of Healthcare Technology and Medicine Vol. 6 No. 1 April 2020

Universitas Ubudiyah Indonesia

e-ISSN : 261109X

TABEL 5.2

KARASTERISTIK RESPONDEN IBU HAMIL TRIMESTER II DAN III DI KEMUKIMAN BUSU KECAMATAN MUTIARA BARAT KABUPATEN PIDIE BERDASARKAN PENDIDIKAN

\begin{tabular}{cccc}
\hline No & Pendidikan & Frekuensi (f) & Persentase (\%) \\
\hline $\mathbf{1}$ & Dasar & 8 & 22,9 \\
$\mathbf{2}$ & Menengah & 22 & 62,9 \\
$\mathbf{3}$ & Tinggi & 5 & 14,2 \\
& Jumlah & 35 & 100 \\
\hline
\end{tabular}

Berdasarkan Tabel 5.2 menunjukkan bahwa dari 35 responden, mayoritas responden berpendidikan menengah yaitu 22 responden $(62,9 \%)$.

3. Analisa univariat

a. Pengetahuan

TABEL 5.3

DISTRIBUSI FREKUENSI PENGETAHUAN IBU HAMIL TRIMESTER II DAN III DI KEMUKIMAN BUSU KECAMATAN MUTIARA BARAT KABUPATEN PIDIE

\begin{tabular}{cccc}
\hline No & Kategori & Frekuensi (f) & Persentase (\%) \\
\hline $\mathbf{1}$ & Baik & 8 & 22,9 \\
$\mathbf{2}$ & Cukup & 11 & 31,4 \\
$\mathbf{3}$ & Kurang & 16 & 45,7 \\
& Jumlah & 35 & 100 \\
\hline
\end{tabular}

Sumber data : Data Primer (diolah tahun 2018)

Berdasarkan Tabel 5.3 diatas menunjukkan bahwa dari 35 responden, mayoritas ibu hamil berpengetahuan kurang sebanyak 16 responden $(45,7 \%)$.

b. Penalakasanaan Breast Care 
Journal of Healthcare Technology and Medicine Vol. 6 No. 1 April 2020

Universitas Ubudiyah Indonesia

e-ISSN : 261109X

TABEL 5.4

DISTRIBUSI FREKUENSI PENATALAKSANAAN BREAST CARE DI KEMUKIMAN BUSU KECAMATAN MUTIARA BARAT KABUPATEN PIDIE

\begin{tabular}{cccc}
\hline No & Kategori & Frekuensi (f) & Persentase (\%) \\
\hline $\mathbf{1}$ & Dilaksanakan & 18 & 51,4 \\
$\mathbf{2}$ & Tidak dilaksanakan & 17 & 48,6 \\
& Jumlah & 35 & 100 \\
\hline
\end{tabular}

Sumber data : Data Primer (diolah tahun 2018)

Berdasarkan Tabel 5.4 diatas menunjukkan bahwa dari 35 responden, mayoritas yang melaksanakan breast care pada saat hamil yaitu sebanyak 18 responden $(51,4 \%)$.

2. Analisa Bivariat

TABEL 5.5

HUBUNGAN PENGETAHUAN IBU HAMIL TRIMESTER II DAN III DENGAN

PENATALAKSANAAN BREAST CARE DI KEMUKIMAN BUSU KECAMATAN MUTIARA BARAT KABUPATEN PIDIE

\begin{tabular}{|c|c|c|c|c|c|c|c|c|c|}
\hline \multirow[t]{3}{*}{ No } & \multirow[t]{3}{*}{ Pengetahuan } & \multicolumn{4}{|c|}{ Breast Care } & \multirow[t]{3}{*}{$\bar{F}$} & \multirow[t]{3}{*}{$\%$} & \multirow{3}{*}{$\begin{array}{l}\mathrm{P} \\
\text { Value }\end{array}$} & \multirow{3}{*}{$\alpha$} \\
\hline & & \multicolumn{2}{|c|}{ Tidak ada } & \multicolumn{2}{|c|}{ Ada } & & & & \\
\hline & & $\mathrm{F}$ & $\%$ & $\mathrm{~F}$ & $\%$ & & & & \\
\hline 1 & Baik & 2 & 25,0 & 6 & 75,0 & 8 & 100 & & \\
\hline 2 & Cukup & 2 & 12,2 & 9 & 81,8 & 11 & 100 & 0002 & 005 \\
\hline 3 & Kurang & 13 & 81,3 & 3 & 18,8 & 16 & 100 & & \\
\hline Jumlah & & 17 & & 18 & & 35 & 100 & & \\
\hline
\end{tabular}

Sumber data : Data Primer (diolah tahun 2018)

Berdasarkan Tabel 5.5 diatas menunjukkan bahwa dari 8 responden yang pengetahuan baik tidak melaksanakan breast care saat hamil sebanyak 2 responden $(25,0 \%)$ dan yang melaksanakan breast care saat hamil sebanyak 6 responden $(75,0 \%)$, dari 11 responden yang berpengetahuan cukup tidak melaksanakan breast care saat hamil sebanyak 2 responden $(12,2 \%)$, dan yang melaksanakan breast care saat hamil sebanyak 9 responden $(81,8 \%)$, 
Journal of Healthcare Technology and Medicine Vol. 6 No. 1 April 2020

Universitas Ubudiyah Indonesia

e-ISSN : 261109X

sedangkan dari 16 responden yang berpengetahuan kurang tidak melaksanakan breast care saat hamil sebanyak 13 responden $(81,3 \%)$ dan yang melaksanakan breast care saat hamil sebanyak 3 responden $(18,8 \%)$.

Hasil analisa statistic menggunakan uji Chi-Square dengan nilai $\mathrm{P}$ value $=$ $0,002<0,05$ hal tersebut berarti Ho ditolak dan Ha diterima, maka Ada Hubungan antara Pengetahuan Ibu Hamil Trimester II dan III Dengan Penatalaksanaan Breast Care Di Kemukiman Busu Kecamatan Mutiara Barat Kabupaten Pidie.

\section{A. Pembahasan}

Berdasarkan Tabel 5.5 dengan menggunakan fisher exact test menunjukkan bahwa dari 8 responden yang pengetahuan baik tidak melaksanakan breast care saat hamil sebanyak 2 responden $(25,0 \%)$ dan yang melaksanakan breast care saat hamil sebanyak 6 responden $(75,0 \%)$, dari 11 responden yang berpengetahuan cukup tidak melaksanakan breast care saat hamil sebanyak 2 responden $(12,2 \%)$, dan yang melaksanakan breast care saat hamil sebanyak 9 responden $(81,8 \%)$, sedangkan dari 16 responden yang berpengetahuan kurang tidak melaksanakan breast care saat hamil sebanyak 13 responden $(81,3 \%)$ dan yang melaksanakan breast care saat hamil sebanyak 3 responden $(18,8 \%)$.

Hasil analisa statistic menggunakan uji Chi-Square dengan nilai $\mathrm{P}$ value $=$ $0,002<0,05$ hal tersebut berarti Ho ditolak dan Ha diterima, maka Ada Hubungan antara Pengetahuan Ibu Hamil Trimester II dan III Dengan Penatalaksanaan Breast Care Di Kemukiman Busu Kecamatan Mutiara Barat Kabupaten Pidie.

Pengetahuan ibu tentang breast care akan mempengaruhi penatalaksanaan breast care selama kehamilannya. Teori lawrence green dalam Notoatmodjo (2010) yang menyatakan bahwa perilaku seseorang di pengaruhi oleh faktor predisposisi, faktor enabling dan faktor reinforcing. Pengetahuan seseorang merupakan faktor reinforcing dalam pembentukan perilaku seseorang. Artinya seseorang akan bertindak apabila orang tersebut mempunyai pengetahuan akan tindakan tersebut. Seseorang akan melakukan breast care sebatas dengan pengetahuannya tentang breast care. Semakin banyak pengetahuan yang ia miliki maka akan semakin terintegrasi dalam tindakan seseorang. Ibu yang mempunyai pengetahuan kurang tentang perawatan payudara, akan menyebabkan orang tersebut tidak akan bertindak. Sehingga pada ibu yang tidak 
Journal of Healthcare Technology and Medicine Vol. 6 No. 1 April 2020

Universitas Ubudiyah Indonesia

e-ISSN : 261109X

tahu atau kurang mengetahui tentang breast care maka tidak akan bertindak dalam perawatan payudara (Breast Care).

Menurut Skinner dalam Notoatmodjo (2010) seorang ahli psikologi, merumuskan bahwa perilaku merupakan respon atau reaksi seseorang terhadap stimulus (rangsangan dari luar). Perilaku manusia dari segi biologis adalah tindakan atau aktivitas dari manusia itu sendiri yang mempunyai bentangan yang sangat luas seperti berjalan, berbicara, menangis, bekerja dan sebagainya.

Menurut Notoatmodjo (2010), perilaku seseorang dipengaruhi oleh pengetahuannya. Karena semakin baik pengetahuannya atau semakin banyak yang ia tahu maka akan mendorong seseorang untuk berperilaku baik pula dan begitu juga sebaliknya.

Berdasarkan hasil penelitian, penulis berasumsi bahwa semakin tinggi pengetahuan ibu maka ibu akan melaksanakan breast care pada masa kehamilan, namun apabila tingkat pengetahuan senderung menurun maka ibu tidak akan melaksanakan breast care pada masa kehamilan.

Berdasarkan Tabel 5.1 karakteristik responden berdasarkan umur menunjukkan bahwa dari 35 responden, mayoritas reseponden berumur antara 20-35 tahun yaitu 27 reponden $(77,1 \%)$.

Usia merupakan salah satu sifat karakteristik tentang orang yang sangat utama. Usia mempunyai hubungan pengalaman terhadap masalah kesehatan/penyakit dan pengambilan keputusan dipengaruhi oleh usia individu tersebut (Noor, 2010). Hal ini disebabkan karena pengalaman diri sendiri maupun orang lain. Hal ini sesuai yang dikemukakan Soekanto (2010) bahwa pengetahuan seseorang dipengaruhi oleh beberapa faktor, diantaranya yaitu pengalaman.

Seperti yang disampaikan oleh Notoadmodjo (2010) yang menyatakan bahwa ada beberapa faktor yang mempengaruhi pengetahuan seperti umur Makin tua umur seseorang maka proses-proses perkembangan mentalnya bertambah baik pada umur tertentu. Daya ingat seseorang data dipengaruhi oleh umur. Maka dapat disimpulkan bahwa bertambahnya umur seseorang akan berpengaruh pada pengetahuan yang diperolehnya, akan tetapi pada umur tertentu seperti usia lanjut kemampuan untuk mengingat sesuatu akan berkurang.

Berdasarkan Tabel 5.2 karakteristik responden bersadasarkan pendidikan menunjukkan bahwa dari 35 responden, mayoritas responden berpendidikan menengah yaitu 22 responden $(62,9 \%)$.

Salah satu faktor yang berpengaruh terhadap pengetahuan adalah pendidikan. Pendidikan diperlukan untuk mendapat informasi misalnya hal-hal 
Journal of Healthcare Technology and Medicine Vol. 6 No. 1 April 2020

Universitas Ubudiyah Indonesia

e-ISSN : 261109X

yang menunjang kesehatan sehingga dapat meningkatkan kualitas hidup. Pendidikan dapat mempengaruhi seseorang termasuk perilaku seseorang akan pola hidup terutama dalam memotivasi untuk berperan serta dalam pembangunan. Pada umumnya makin tinggi pendidikan seseorang makin mudah menerima informasi (Wawan dan Dewi, 2011).

\section{KESIMPULAN}

Setelah dilakukan uji statistik tentang Hubungan antara Pengetahuan Ibu Hamil Trimester II dan III Dengan Penatalaksanaan Breast Care Di Kemukiman Busu Kecamatan Mutiara Barat Kabupaten Pidie, dapat disimpulkan ada hubungan antara pengetahuan ibu hamil dengan Penatalaksanaan Breast Care, dengan nilai $\mathrm{P}$ value $=$ $0,002<0,05$.

\section{SARAN}

Penelitian ini di harapkan dapat di jadikan Sebagai bahan informasi dan penambah pengetahuan masyarakat tentang peningkatan pengetahuan tentang penatalaksanaan Breast Care.

\section{DAFTAR PUSTAKA}

Abdul Bari Saifuddin. 2010. Ilmu Kebidanan, edisi.4. Jakarta: Bina Pustaka Sarwono Prawirohardjo

Andriani, Durri. Dkk. (2011). Metode Penelitian. Universitas Terbuka.

Anik Maryunani, 2012, Ilmu Kesehatan Anak, Jakarta : CV. Trans Info Media.

Arikunto, S., 2009. Prosedur Penelitian Suatu Pendekatan Praktik. Edisi Revisi 6. Jakarta : Rineka Cipta.

Depkes RI. Profil Kesehatan Indonesia Tahun 2014. Jakarta: Departemen Kesehatan Republik Indonesia; 2013.

Effendy, Onong Uchyana. 2008. Ilmu Komunikasi: Teori dan Prakteknya, Bandung : Remaja Rosdakarya.

Manuaba, I. B. G. 2011. Kepanitraan Klinik Obstetri \& Genekologi. Jakarta: EGC. 
Journal of Healthcare Technology and Medicine Vol. 6 No. 1 April 2020

Universitas Ubudiyah Indonesia

e-ISSN : 261109X

Norma, Nita D, Mustika Dwi S. 2011. Asuhan Kebidanan Patologi. Yogyakarta: Nuha Medika

Notoatmodjo, S. 2011. Ilmu Perilaku Kesehatan. Jakarta: Rineka Cipta. 2011. Ilmu Perilaku Kesehatan. Jakarta: Rineka Cipta. 2014. Ilmu Perilaku Kesehatan. Jakarta: Rineka Cipta.

Pramitasari RD, Saryono. 2009. Perawatan Payudara. Yogyakarta. Mitra Cendekia.

Prawirohardjo, Sarwono. 2010. Ilmu Kebidanan. Jakarta: Yayasan Bina Pustaka Sarwono Prawirohardjo

Rulina Suradi. 2004. Pemberian ASI pada berbagai situasi tertentu. Dalam Partini P. Rustam, Mochtar. 2009. Sinopsis Obstetri: Obstetri Fisiologi, Obstetri Patologi. Jakarta: EGC.

Trihono: Hot topics in pediatrics II. Edisi 1. Jakarta: Balai Penerbit FKUI. hal. 63-4 WHO. Maternal Mortality: World Health Organization; 2014. 